\title{
Rapid Access to Polyprenylated Phloroglucinols via Alkylative Dearomatization-Annulation: Total Synthesis of $( \pm)$-Clusianone ${ }^{1}$
}

\author{
Ji Qi and John A. Porco Jr. \\ Department of Chemistry and Center for Chemical Methodology and Library Development (CMLD- \\ BU), Boston University, Boston, Massachusetts 02215
}

A number of polyprenylated phloroglucinol natural products bearing densely functionalized bicyclo[3.3.1]nonane-1,3,5-trione core structures have been reported from plant sources (Figure 1). ${ }^{2}$ These include clusianone 1 and its $\mathrm{C} 7$ epimer $\mathbf{2}, 3$ isolated from the floral resins of Clusia species, nemorosone $\mathbf{3}^{, 4}$ a regioisomer of $\mathbf{1}$, and the adamantane-containing polyprenylated phloroglucinol hyperibone $\mathrm{K} \mathrm{4.}{ }^{5} \mathrm{In}$ light of their challenging structures and promising biological activities, a number of synthetic efforts have been reported. ${ }^{6}$ Recently, impressive syntheses of ( \pm )-garsubellin $\mathbf{A}^{7}$ and (+)-clusianone $\mathbf{1}^{8}$ have been accomplished further underscoring interest in this target class. In this Communication, we report our initial studies on the synthesis of polyprenylated phloroglucinols employing a tandem alkylative dearomatization-annulation process to rapidly construct the bicyclo[3.3.1]nonane-1,3,5-trione core.

Our approach to clusianone (Figure 1, 1) and related polyprenylated phloroglucinols was inspired by biosynthetic considerations ${ }^{4}$ as well as the facile alkylative dearomatization observed for clusiaphenone B $\mathbf{5}^{9}$ (Scheme 1). Prenylation of 5 (prenyl bromide, aq. $\mathrm{KOH}$ ) afforded 6 (40\% yield), ${ }^{10}$ presumably through the intermediacy of grandone $7 .{ }^{11}$ This transformation underscored the propensity for sequential bis-alkylation of the phloroglucinol core and suggested a concise approach to clusianone and related targets involving alkylative dearomatization-annulation. Recent reports ${ }^{12}$ have described sequential Michael-elimination reactions of enolates with acrylates to prepare bicyclo[3.3.1]nonane core structures. Based on the alkylation sequence $\mathbf{5} \rightarrow \mathbf{7} \rightarrow \mathbf{6}$, we considered whether an anionic species 8 derived from clusiaphenone B $\mathbf{5}$ may participate in conjugate addition with a Michael acceptor such as $\mathbf{9}$ to afford dearomatized product 10. Intramolecular conjugate addition completes the synthesis of 11 which possesses the clusianone framework.

The synthesis of the polyisoprenylated benzophenone clusiaphenone B 5 commenced with $C$ prenylation 13 of acylphloroglucinol 12 (Scheme 2). ${ }^{14}$ After considerable experimentation, we found that treatment of 5 with LiHMDS ( 3 equiv.) followed by addition of $\alpha$-acetoxymethyl acrylate $13^{12 \mathrm{a}}$ ( 2 equiv.) at $0^{\circ} \mathrm{C}$ led to an efficient, highly diastereoselective dearomatizationannulation process in which an additional Michael-elimination event had unexpectedly occurred to afford 14 (70\% yield). The backbone structure of 14 was suggested by computational-assisted structure elucidation based on ${ }^{1} \mathrm{H},{ }^{13} \mathrm{C},{ }^{1} \mathrm{H}-{ }^{1} \mathrm{H}$ COSY, HMQC, and HMBC data. ${ }^{10}$ The relative stereochemistry of $\mathbf{1 4}$ was determined by acylation and $\mathrm{x}$-ray crystal structure analysis of the derived $p$-bromobenzoate ester $\mathbf{1 5}$. The stereochemistry of the final Michael-elimination event is likely dictated by the approach of $\mathbf{1 3}$ from the convex face of the enolate intermediate $\mathbf{1 6}$ which has been observed for transformations in related compounds. $7 \mathrm{~b}$ 
In order to evaluate the scope of the dearomatization-annulation process, we examined the reaction of substituted phloroglucinols with a variety of substituted $\alpha$-acetoxyacrylates (Table 1). Phloroglucinol 17 bearing an alkyl-aryl ketone reacted with 13 in a similar manner to 5 (LiHMDS, THF, $0^{\circ} \mathrm{C}$ ) to afford the bicyclo[3.3.1]nonane derivative 18 (entry 1). Reaction of acrylonitrile 1915 with $\mathbf{5}$ under similar conditions afforded a mixture of products. Reduction of both the equivalents of Michael acceptor and base led to the production of $\mathbf{2 0}$ (41\% yield) after enol methylation (entry 2). This result supports the lower reactivity of acrylonitriles as Michael acceptors in comparison to acrylate 13. Using the more sterically hindered $\alpha$ acetoxymethyl acceptor $9^{10}$ (entry 3), annulation and enol methylation were found to proceed cleanly to afford the clusianone-type compound 21 and its epimer 22 (d.r. = 4:1). The stereochemical assignment of $\mathbf{2 1}$ and $\mathbf{2 2}$ were based on nOe experiments and comparison to coupling constants reported for $\mathbf{1}$ and $2 .{ }^{16}$ Reactions of the electron deficient Michael acceptors trifluoroethyl ester $\mathbf{2 3}^{10}$ (entry 4) and sulfone $\mathbf{2 5}^{10}$ (entry 5) afforded products $\mathbf{2 4}$ and $\mathbf{2 6}$ leading us to suspect epimerization of the $\mathrm{C} 7$ stereocenter during the tandem process (vide infra).

In order to access clusianone, we considered use of $\alpha$-acetoxy enal $27^{10}$ in the annulation process in order to install an aldehyde handle for prenyl installation (Scheme 3). Accordingly, treatment of 5 with KHMDS (2.1 equiv) and 27 (1.1 equiv.) in THF $\left(65^{\circ} \mathrm{C}\right)$ led to the generation of desired annulation product. In order to facilitate isolation and further characterization, enol methylation afforded $\mathbf{2 8}$ (one methyl ether isomer shown for clarity) as a mixture of regioisomers (54\% yield, two steps). Addition of vinyl magnesium bromide to aldehyde 28, followed by acetylation of the emerged secondary alcohol, afforded allylic acetate 29. Palladium-catalyzed formate reduction ${ }^{17}$ of allylic acetate 29 was followed by olefin crossmetathesis with 2-methyl-2-butene according to the Grubbs's protocol ${ }^{18}$ to afford clusianone methyl ether 30 (80\%, two steps). Final nucleophilic demethylation ${ }^{8 a}, \mathrm{c}$ generated $( \pm)$ clusianone as a mixture of enol tautomers. $16 \mathrm{~b}$

As previously described, we have found that the dearomatization-annulation process favors production of clusianone-type stereoisomers. We thus initiated experiments to probe details of the suspected epimerization of the aldehyde-bearing stereocenter leading to $\mathbf{2 8}$ (Scheme 3). Interestingly, treatment of $\mathbf{5}$ with enal $\mathbf{2 7}$ in the presence of KHMDS at $0{ }^{\circ} \mathrm{C}$ unexpectedly led to the production of the complex adamantane $\mathbf{3 1}$ (Scheme 4). The structure of $\mathbf{3 1}$ is closely related to the natural product hyperibone $\mathrm{K}$ (Figure $1, \mathbf{4}$ ). This compound is apparently produced from the kinetic protonation product $\mathbf{3 2}$ followed by a stereoselective intramolecular aldol reaction. Further treatment of $\mathbf{3 1}$ with KHMDS at $65^{\circ} \mathrm{C}$ led to the formation of $\mathbf{3 3} \mathrm{via}$ a retro-aldol epimerization process. These initial studies support base-catalyzed epimerization leading to clusianone precursor $\mathbf{2 8}$ (Scheme 3 ) and related compound ( $c f$. Table 1 ) and establish a possible route to adamantane-containing polyprenylated phloroglucinols including hyperibone K (4, Figure 1).

In summary, we have developed a concise approach to the bicyclo[3.3.1]nonane framework of the polyprenylated phloroglucinol natural products utilizing alkylative dearomatizationannulation. A related approach has been used to access an adamantane structure with four all carbon quaternary centers formed in one step from a phloroglucinol precursor. Further applications of the methodology to the synthesis of additional polyprenylated phloroglucinol natural products are currently in progress and will be reported in due course.

\section{Supplementary Material}

Refer to Web version on PubMed Central for supplementary material. 


\section{Acknowledgment}

We thank the National Institutes of Health (GM-62842), the Novartis Institutes for BioMedical Research, and Merck Research Laboratories for research support and Mr. Ang Li (The Scripps Research Institute) and Drs. Jianglong Zhu and Shun Su (Boston University) for helpful discussions.

\section{References}

1. Presented in part at the 233rd American Chemical Society National meeting; March 25-29, 2007; Chicago, Illinois. ORGN abstract 383

2. Ciochina C, Grossman RB. Chem. Rev 2006;106:3963. [PubMed: 16967926]

3. Mccandlish LE, Hanson JC, Stout GH. Acta Cryst 1976;B32:1793.

4. Cuesta-Rubio O, Velez-Castro H, Frontana-Uribe BA, Cardenas J. Phytochemistry 2001;57:279. [PubMed: 11382245]

5. Tanaka N, Takaishi Y, Shikishima Y, Nakanishi Y, Bastow K, Lee KH, Honda G, Ito M, Takeda Y, Kodzhimatov OK, Ashurmetov O. J. Nat. Prod 2004;67:1870. [PubMed: 15568778]

6. Select examples: (a) Spessard SJ, Stoltz BM. Org. Lett 2002;4:1943. [PubMed: 12027653] (b) Ciochina R, Grossman RB. Org. Lett 2003;5:4619. [PubMed: 14627398] (c) Nicolaou KC, Carenzi GEA, Jeso V. Angew. Chem. Int. Ed 2005;44:3895. (d) Mehta G, Bera MK. Tetrahedron Lett 2006;47:689.

7. (a) Kuramochi A, Usuda H, Yamatsugu K, Kanai M, Shibasaki M. J. Am. Chem. Soc 2005;127:14200. [PubMed: 16218611] (b) Siegel DR, Danishefsky SJ. J. Am. Chem. Soc 2006;128:1048. [PubMed: 16433500]

8. (a) Rodeschini V, Simpkins NS, Wilson C. J. Org. Chem 2007;72:4265. [PubMed: 17465570] (b) Nuhant P, David M, Pouplin T, Delpech B, Marazano C. Org. Lett 2007;9:287. [PubMed: 17217286] (c) Ahmad NM, Rodeschini V, Simpkins NS, Ward SE, Blake AJ. J. Org. Chem 2007;72:4803. [PubMed: 17530804]

9. Delle Monache F, Monache GD, Gacs-Baitz E. Phytochemistry 1991;30:2003.

10. See Supporting Information for complete experimental details.

11. Drewett KG, Laws DRJ. J. Inst. Brew 1970;76:188.

12. (a) Takagi R, Nerio T, Miwa Y, Matsumura S, Ohkata K. Tetrahedron Lett 2004;45:7401. (b) Takagi R, Miwa Y, Matsumura S, Ohkata K. J. Org. Chem 2005;70:8587. [PubMed: 16209615] (c) Takagi R, Miwa Y, Nerio T, Inoue Y, Matsumura S. Org. Biomol. Chem 2007;5:286. [PubMed: 17205172] 13. Sun Y, Li Y, Zhao L, Xiao L. Hecheng Huaxue 1995;3:127.

14. Mondal M, Puranik VG, Argade NP. J. Org. Chem 2007;72:2068. [PubMed: 17298098]

15. Ma S, Yu S, Peng Z, Guo H. J. Org. Chem 2006;71:9865. [PubMed: 17168610]

16. (a) dos Santos MH, Nage TJ, Braz-Filho R, Lula IS, Speziali NL. Magn. Reson. Chem 2001;39:155.

(b) Piccinelli AL, Cuesta-Rubio O, Chica MB, Mahmood N, Pagano B, Avone M, Barone V, Rastrell L. Tetrahedron 2005;61:8206.

17. Hughes G, Lautens M, Wen C. Org. Lett 2000;2:107. [PubMed: 10814258]

18. Chatterjee AK, Sanders DP, Grubbs RH. Org. Lett 2002;4:1939. [PubMed: 12027652] 


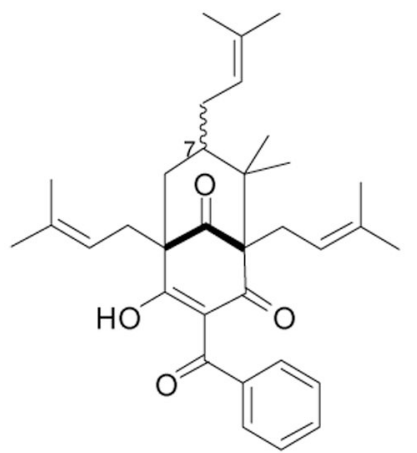

clusianone $1(7 \beta)$ 7-epi-clusianone $2(7 \alpha)$

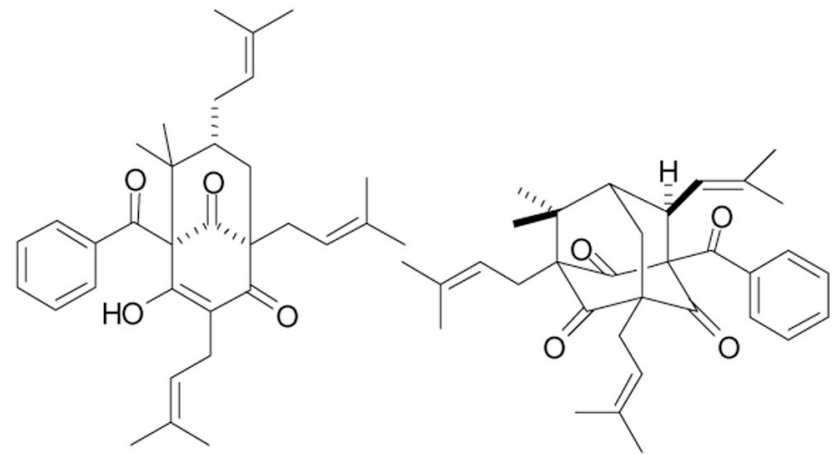

hyperibone K 4

Figure 1.

Polyisoprenylated Phloroglucinol Natural Products 


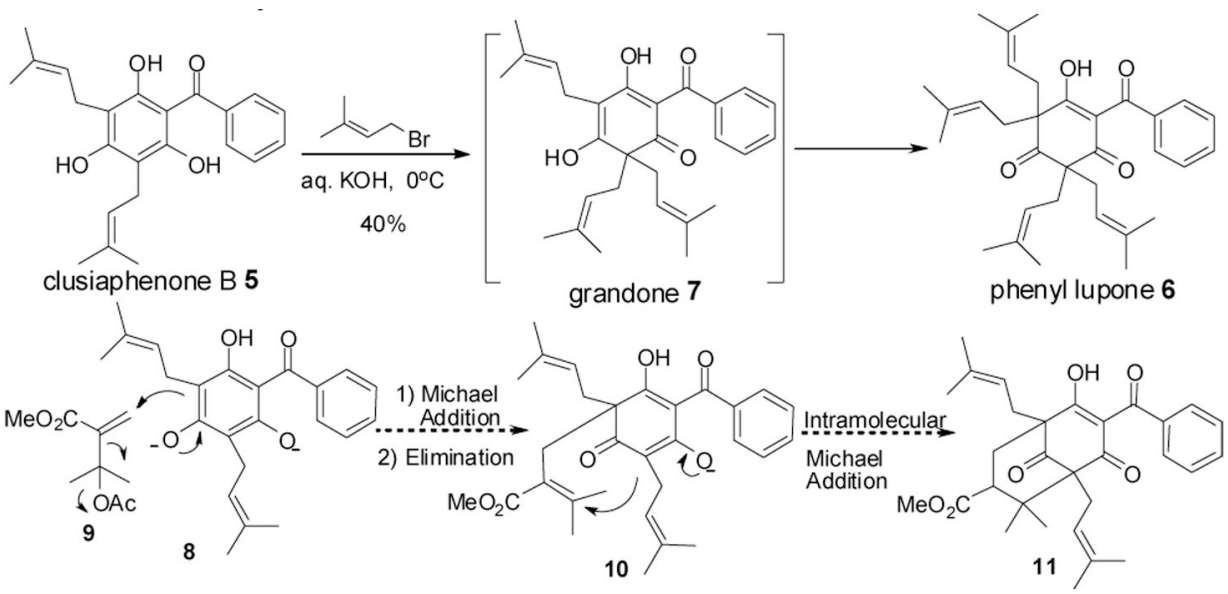

Scheme 1.

Synthetic Plan for Clusianone 


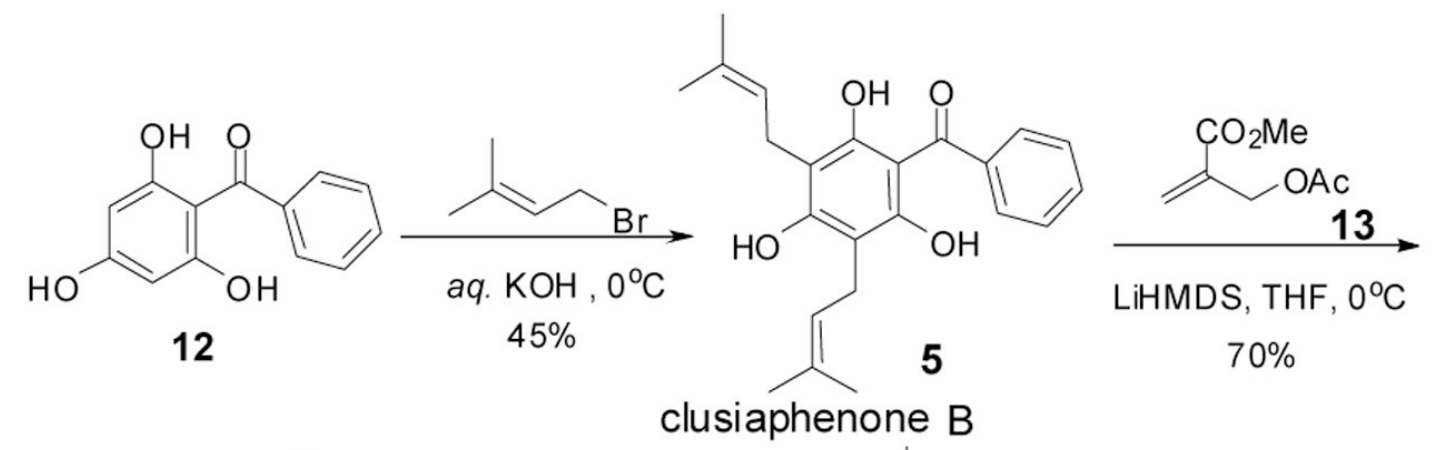

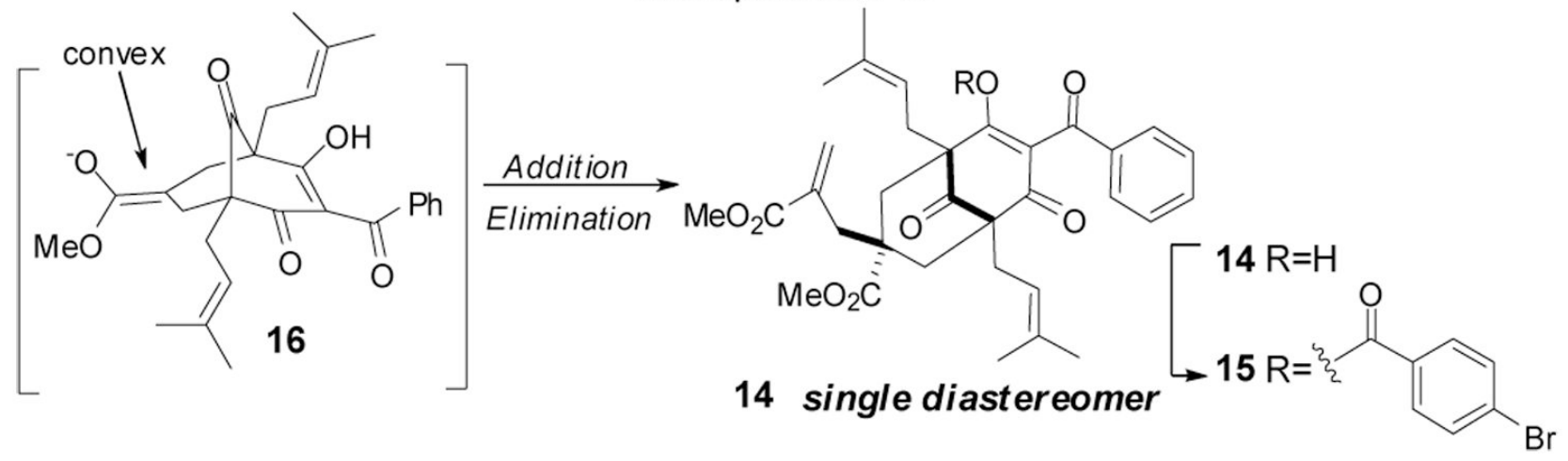

Scheme 2.

Model Studies 

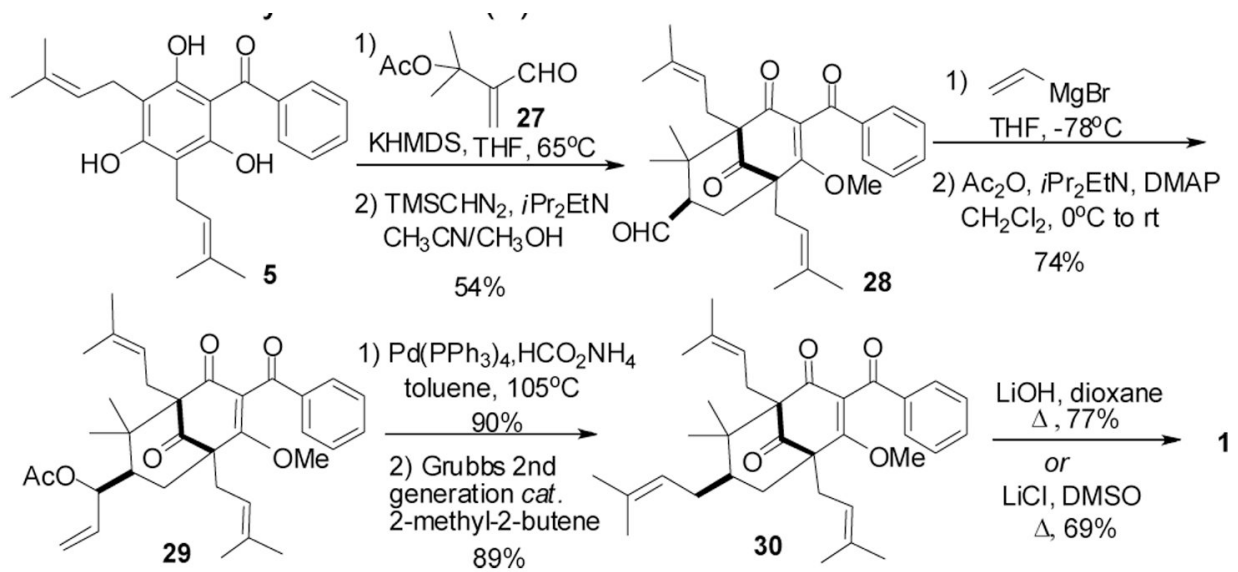

1) $\mathrm{Pd}\left(\mathrm{PPh}_{3}\right)_{4}, \mathrm{HCO}_{2} \mathrm{NH}_{4}$ toluene, $105^{\circ} \mathrm{C}$

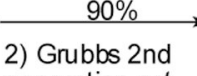
generation cat. 2-methyl-2-butene $89 \%$

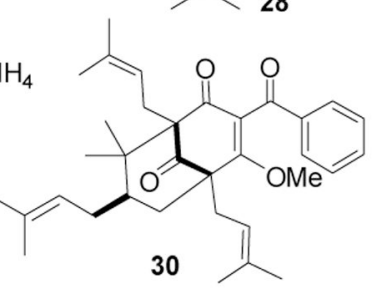

$\mathrm{LiOH}$, dioxane

$\mathrm{LiCl}, \mathrm{DMSO}$

$\Delta, 69 \%$

Scheme 3.

Synthesis of $( \pm)$-clusianone 


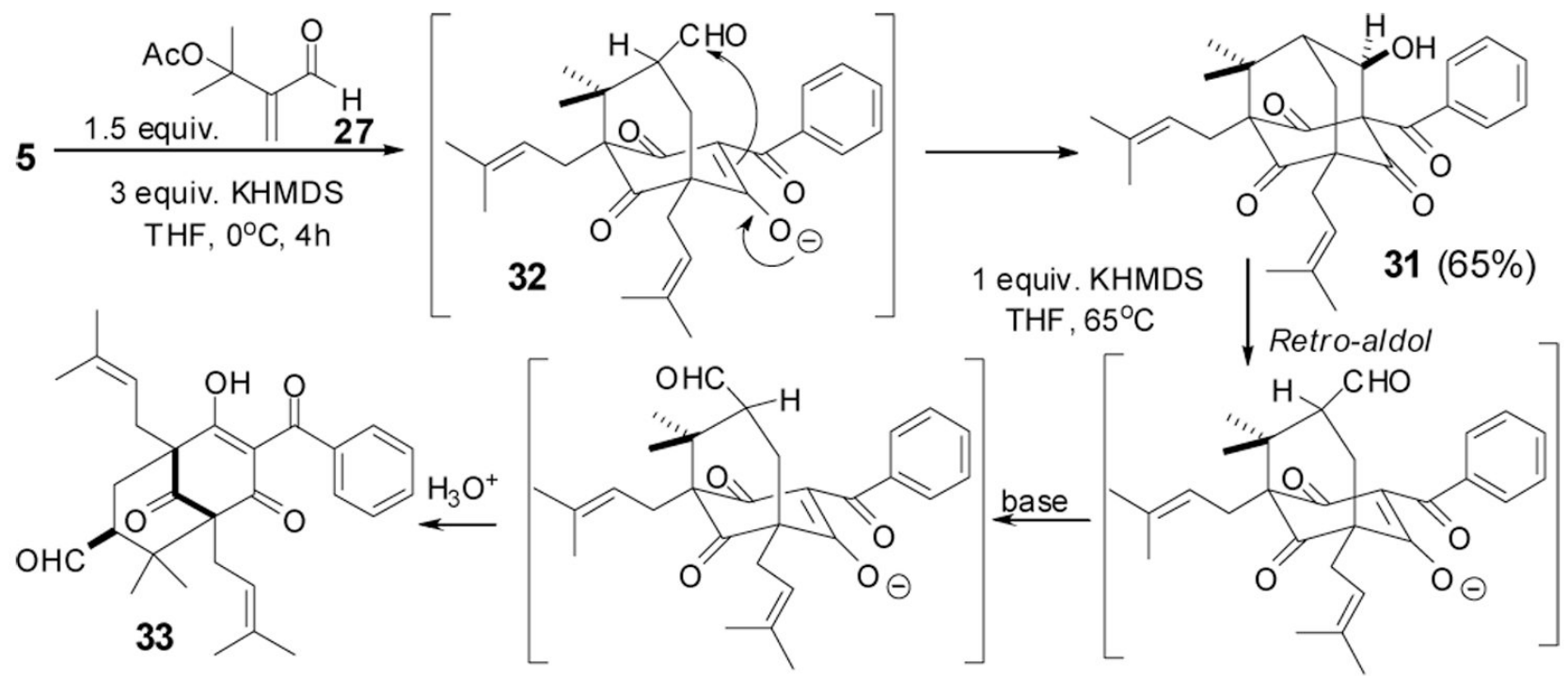

Scheme 4.

Access to an Adamantane Framework 
Table 1

Alkylative Dearomatization-Annulation

\begin{tabular}{lll}
\hline entry & substrates & Michael acceptors
\end{tabular}
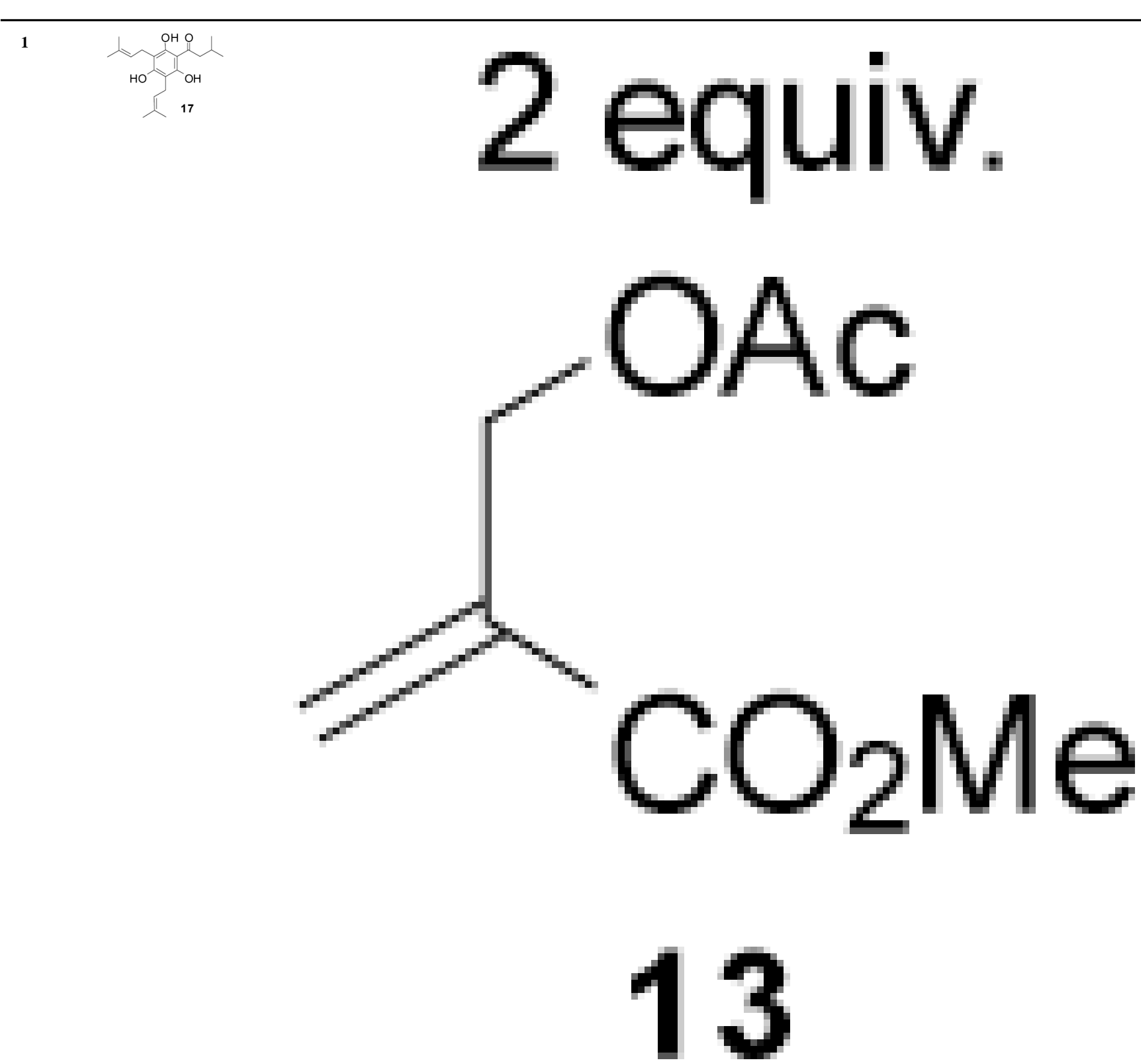

2
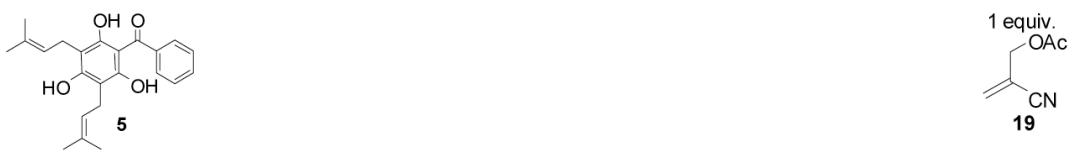
entry

3
5

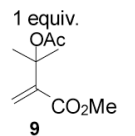

${ }^{\mathrm{CO}_{2} \mathrm{Me}}$ 


\begin{tabular}{|c|c|c|}
\hline entry & substrates & Michael acceptors \\
\hline 4 & 5 & $\begin{array}{l}1 \text { equiv. } \\
\mathrm{CO}_{2} \mathrm{CH}_{2} \mathrm{CF}_{3}\end{array}$ \\
\hline
\end{tabular}

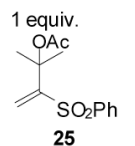

5 5

${ }^{a}$ Yield after enol methylation using $\mathrm{TMSCHN}_{2}$ (2 equiv.) and $i \operatorname{Pr} 2 \mathrm{EtN}$ (1.5 equiv.)

${ }^{b}$ Mixture of enol ether isomers produced, one shown for clarity. 